\title{
Report on Hydrogen Isotope
}

Permeability/Hermeticity of SiC-based Cladding

Nuclear Technology

Research and Development

Approved for public release. Distribution is unlimited.

Prepared for

U.S. Department of Energy Advanced Fuel Campaign X. Hu, T. Koyanagi, Y. Katoh Oak Ridge National Laboratory May 2019 M4FT-19OR020202062 ORNL/TM-2019/1187 


\section{DISCLAIMER}

This information was prepared as an account of work sponsored by an agency of the U.S. Government. Neither the U.S. Government nor any agency thereof, nor any of their employees, makes any warranty, expressed or implied, or assumes any legal liability or responsibility for the accuracy, completeness, or usefulness, of any information, apparatus, product, or process disclosed, or represents that its use would not infringe privately owned rights. References herein to any specific commercial product, process, or service by trade name, trade mark, manufacturer, or otherwise, does not necessarily constitute or imply its endorsement, recommendation, or favoring by the U.S. Government or any agency thereof. The views and opinions of authors expressed herein do not necessarily state or reflect those of the U.S. Government or any agency thereof. 


\section{SUMMARY}

The continuous $\mathrm{SiC}$ fiber-reinforced $\mathrm{SiC}$ matrix ceramic composites have been perceived as one of the leading candidate materials for accident tolerant fuel cladding in light water reactors. Potential loss of the fission products containment due to penetrating cracking has been identified as one of the most critical technical issues for SiC-based nuclear fuel cladding. As such, evaluation of the hermeticity of $\mathrm{SiC} / \mathrm{SiC}$ composite cladding subject to ligh water reactor (LWR) relevant environment is critically important. In last two years, we have established the capability to measure the gas permeation flux through tubular samples and reported preliminary results of the hermeticity of unirradiated $\mathrm{SiC} / \mathrm{SiC}$ composite tubes and one neutron irradiated Chemical Vapor Deposition (CVD) SiC tube. In this study, a permeation testing station was employed to measure the deuterium permeation of as-fabricated and coated $\mathrm{SiC} / \mathrm{SiC}$ composite tubes following high heat flux neutron irradiation. The results indicate that CVD SiC tubes survived both the high and low heat flux neutron irradiations. $\mathrm{SiC} / \mathrm{SiC}$ composite tubes with and without coating following high heat flux neutron irradiation lost gas tightness. Coating on $\mathrm{SiC} / \mathrm{SiC}$ composite tubes helped to reduce the deuterium permeation flux compared to the uncoated samples. Better coating and/or improved architectural design and manufacturing quality is needed to ensure the hermeticity of $\mathrm{SiC} / \mathrm{SiC}$ composite tubes. A more robust understanding of the correlation between applied gas pressure and measured leak rate is needed. 
INTENTIONALLY BLANK 


\section{CONTENTS}

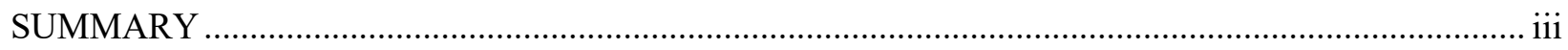

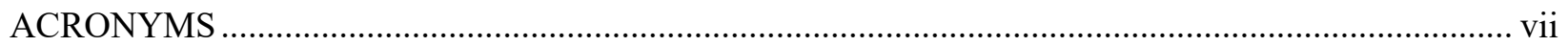

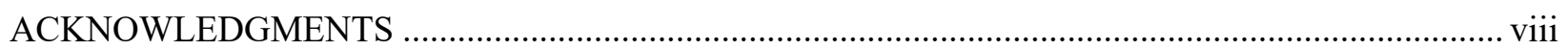

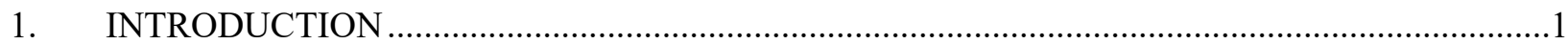

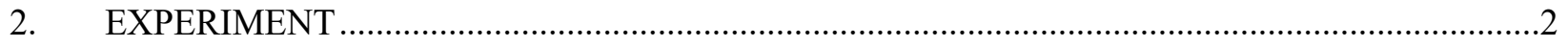

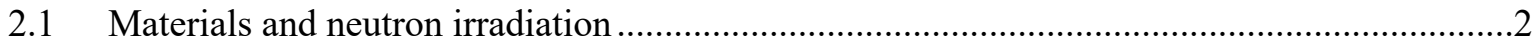

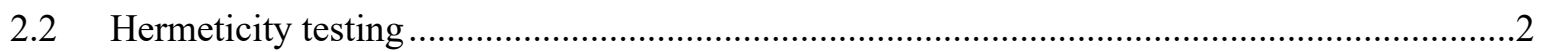

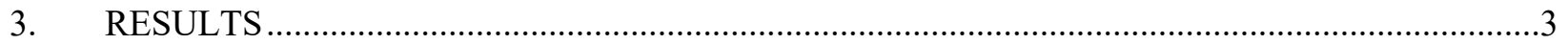

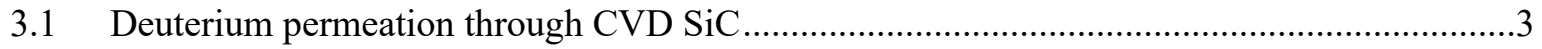

3.2 Deuterium permeation of neutron-irradiated $\mathrm{SiC} / \mathrm{SiC}$ composite tubes ................................5

3.3 Deuterium permeation of neutron-irradiated coated $\mathrm{SiC} / \mathrm{SiC}$ composite tubes .......................6

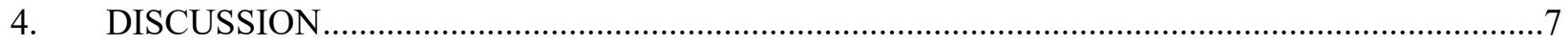

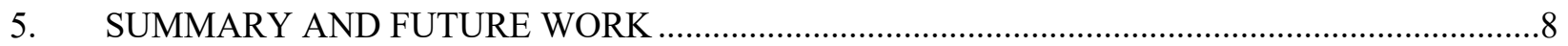

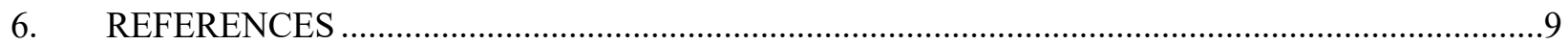




\section{FIGURES}

Figure 1. Deuterium permeation testing of (a) unirradiated CVD SiC tube, (b) CVD SiC-D following high heat flux neutron irradiation, and (c) CVD SiC-F following high heat flux neutron irradiation. Important gases in the background are also shown.

Figure 2. Deuterium leak rate of $\mathrm{SiC} / \mathrm{SiC}$ composite tubes following neutron irradiation $\left(300 \sim 500^{\circ} \mathrm{C}, 2 \mathrm{dpa}, \mathrm{HFIR}\right)$ under high (HHF) and low (LHF) heat flux as a function of deuterium pressure within the tubes.

Figure 3. Deuterium leak rate of coated $\mathrm{SiC} / \mathrm{SiC}$ composite tubes following neutron irradiation $\left(300 \sim 500^{\circ} \mathrm{C}, 2 \mathrm{dpa}, \mathrm{HFIR}\right)$ under high and low heat flux as a function of helium pressure within the tubes.

Figure 4. Helium and deuterium permeation flux of SA3-4 following high heat flux neutron irradiation as a function of feeding gas pressure. Dashed line is the prediction using Hagen-Poiseuille model. 


\title{
ACRONYMS
}

\author{
AFC Advanced Fuels Campaign \\ ATF Accident Tolerant Fuel \\ CEA The French Alternative Energies and Atomic Energy Commission \\ CVD Chemical Vapor Deposition \\ DOE US Department of Energy \\ dpa Displacement Per Atom \\ FeCrAl Iron-Chromium-Aluminum Alloy \\ GA General Atomics \\ HFIR High Flux Isotope Reactor \\ HHF High Heat Flux \\ KAERI Korea Atomic Energy Research Institute \\ LAMDA Low Activation Materials Development and Analysis laboratory \\ LHF Low Heat Flux \\ LWR Light Water Reactor \\ ORNL Oak Ridge National Laboratory \\ RUS Resonant Ultrasound Spectroscopy \\ SiC Silicon Carbide \\ $\mathrm{SiC} / \mathrm{SiC} \quad \mathrm{SiC}$ fiber reinforced $\mathrm{SiC}$ matrix composites
}




\section{ACKNOWLEDGMENTS}

This work was supported by the US Department of Energy Office of Nuclear Energy (DOE-NE) Advanced Fuels Campaign (AFC). We thank GA, KAERI, and CEA for providing the $\mathrm{SiC} / \mathrm{SiC}$ tubes for neutron irradiation. This research used resources at the High Flux Isotope Reactor, a DOE Office of Science User Facility operated by ORNL. 


\section{REPORT ON HYDROGEN ISOTOPE PERMEABILITY/HERMETICITY OF SIC-BASED CLADDING}

\section{INTRODUCTION}

Since the 2011 Japan Fukushima nuclear disaster, a new concept of nuclear fuel, accident tolerant fuel (ATF), has been emerging in the nuclear engineering and materials community [1] [2] [3]. ATF aims to enlarge the safety margins of the current light water reactors (LWRs) under design basis or beyond design basis accident scenarios. In the current nuclear reactor fleet, zirconium alloys are the primary fuel cladding and core structural materials. However, zirconium alloys are vulnerable to catastrophic failure in severe accidents [4], which is attributed primarily to the rapid oxidation kinetics of zirconium in a high temperature steam environment [5]. As the first safety boundary of nuclear reactors, alternative fuel cladding materials with enhanced oxidation resistance have been perceived to improve the accident tolerance of nuclear fuels. FeCrAl alloys [3] and silicon carbide ( $\mathrm{SiC})$ fiber reinforced $\mathrm{SiC}$ matrix $(\mathrm{SiC} / \mathrm{SiC})$ composites [6] are the two leading candidate ATF cladding materials. Oxidation rates for these materials are several orders of magnitude lower than that of zirconium alloys [4]. The reduced oxidation rates in these materials lead to reduced heating and hydrogen generation in the core as a result of this exothermic reaction, which ultimately leads to a slower rate of temperature rise in the reactor core.

The implementation of $\mathrm{SiC} / \mathrm{SiC}$ composite cladding in LWRs requires a thorough understanding and characterization of the composite cladding before and after neutron irradiation, including the mechanical properties, hermeticity, and performance of the environmental barrier coating used to enhance the hydrothermal corrosion resistance and gas tightness. In addition to the enhanced accident tolerance resulting from the use of the continuous fiber $\mathrm{SiC} / \mathrm{SiC}$ composite cladding, a primary function of the cladding itself is to maintain an impermeable barrier to prevent fission gas release from the fuel into the reactor primary coolants. A criterion of $\mathrm{SiC} / \mathrm{SiC}$ composite cladding failure is the loss of gas tightness. Any increase in the extent of fission gas release from the fuel will be directly proportional to an increase in the radioactivity in the primary coolant and the fission gas (e.g., tritium) release to the environment. Moreover, helium is used as the heat conduction medium between the fuel and the cladding. A loss of hermeticity would lead to the release of helium. As a consequence, the heat produced in the fuel could not be removed efficiently and the probability of fuel failure would increase. The gas tightness of the as-fabricated and coated $\mathrm{SiC} / \mathrm{SiC}$ composite tubes needs to be tested to determine whether this criterion is met for their application in LWRs.

Gas permeability data for $\mathrm{SiC}$ and $\mathrm{SiC} / \mathrm{SiC}$ composites in tubular configurations is very limited, especially for samples subjected to neutron irradiation. It is well known that hydrogen permeability in monolithic $\mathrm{SiC}$ is extremely low, $\sim$ ten orders of magnitude lower than that in stainless steels. Therefore, SiC is usually used as barrier for hydrogen isotopes [7] [8]. Hydrogen permeability in SiC is strongly dependent on the manufacturing methods and the quality of the samples produced. Chemical vapor deposition (CVD) beta $\mathrm{SiC}$ has showed the lowest hydrogen permeability [8]. Hino et al. measured the helium gas permeability of planar $\mathrm{SiC} / \mathrm{SiC}$ composite samples. The measured helium permeability had a wide range from $10^{-11}$ to $10^{-5}$ $\mathrm{m}^{2} / \mathrm{s}$, roughly dependent on the pore structure of the $\mathrm{SiC}$ fiber bundle and $\mathrm{SiC}$ matrix layers [9] [10]. Since $\mathrm{SiC} / \mathrm{SiC}$ composites were perceived as a promising ATF cladding material, a research group at General Atomics investigated the gas tightness of tubular $\mathrm{SiC}$ and $\mathrm{SiC} / \mathrm{SiC}$ composite samples using a mobile helium leak detector [11] [12] to characterize the quality of the as-fabricated SiC-based claddings. 
However, hydrogen isotope permeation data of $\mathrm{SiC} / \mathrm{SiC}$ composite tubes is not available. It is well known that a large amount of tritium is produced in nuclear fuel rod through thernary fission, with a yield of $8 \times 10^{-}$ ${ }^{5}$ atoms/fission (> 12,000 Ci per year for a typical $1000 \mathrm{MWe}$ plant) [13]. The high mobility of tritium allows it to permeat the cladding and enter the primary coolant which is not desired. The extent of the permeation depends on clad type. The permeation flux of hydrogen is also an indicator of the gas tightness of the tested tubes. In last two years, we have established the experimental capability to evaluate the hermeticity of tubular samples and reported the helium and deuterium permeation flux of as-fabricated $\mathrm{CVD}$ and $\mathrm{SiC} / \mathrm{SiC}$ tubes and one neutron irradiated CVD SiC tube [14]. In this report, we will show our recent work to investigate the deuterium permeation through $\mathrm{SiC} / \mathrm{SiC}$ composite tubes before and after neutron irradiation by using the permeation testing station at ORNL.

\section{EXPERIMENT}

\subsection{Materials and neutron irradiation}

The materials studied include monolithic high purity CVD SiC tubes machined from CVD SiC purchased from Dow Chemical Co., SiC/SiC composite tubes provided by GA, KAERI and CEA, coated SiC/SiC composite tubes $(\mathrm{CrN}, \mathrm{Cr}$, and $\mathrm{TiN})$ using cathodic arc physical vapor deposition. A special irradiation vehicle was designed and fabricated to test SiC-based cladding under conditions representative of LWR in order to validate thermal-mechanical models of stress states in the studied materials due to irradiation swelling and differential thermal expansion. The design allows for a constant tube outer surface temperature in the range of $300 \sim 350^{\circ} \mathrm{C}$ under a representative high heat flux $\left(\sim 0.66 \mathrm{MW} / \mathrm{m}^{2}\right)$ during one cycle of irradiation in HFIR (equivalent to $2 \mathrm{dpa}$ ). More details regarding the design of this irradiation capsule can be found in Ref. [15]. In addition, conventional neutron irradiation (tube samples contained in irradiation capsule without any internal heater) of $\mathrm{SiC} / \mathrm{SiC}$ composite tubes in HFIR was also performed, which is called 'low heat flux' neutron irradiation throughout this report.

\subsection{Hermeticity testing}

Gas permeation flux through SiC-based claddings is considered an important indicator to evaluate the hermeticity of the studied materials. The term of "permeation testing" encompasses the gas leakage measurements due to physical openings through the walls of the materials (e.g, penetrating cracking) and the actual gas permeability (an intrinsic physical property, equal to the product of diffusivity and solubility) in a material. The testing methods for both parameters are the same. A permeation testing system has been constructed in the Low Activation Materials Development and Analysis (LAMDA) lab at ORNL that is capable of measuring helium, deuterium and hydrogen permeation flux through the studied materials as a function of the feeding gas pressure. More details of this system could be found in Ref. [14]. 


\section{RESULTS}

\subsection{Deuterium permeation through CVD SiC}

$\mathrm{SiC}$ is perceived as a candidate tritium barrier in fusion reactors due to its extremely low hydrogen permeability $\left(<1 \times 10^{-21} \mathrm{~mol} \mathrm{H}_{2} \mathrm{~m}^{-1} \mathrm{~s}^{-1} \mathrm{MPa}^{-1 / 2}\right.$, when temperature is lower than $250^{\circ} \mathrm{C}$ [7]). Therefore, the deuterium permeation flux through CVD SiC will be undetectable by using the current system, of which the resolution is $1 \times 10^{-12} \mathrm{~atm}-\mathrm{cc} / \mathrm{sec}$. Figure 1(a) shows the deuterium permeation testing results of CVD $\mathrm{SiC}$ tubes in the unirradiated condition. Only background signal was measured, indicating the tested sample is hermetic. In reference [14], we reported the hermetic performance of one CVD SiC tube following high heat flux neutron irradiation. In order to improve confidence on the results, here we performed hermeticity testing on two more CVD SiC tubes under the same irradiation condition. Figure 1(b) and (c) shows the deuterium permeation testing results of two CVD SiC tubes following high heat flux neutron irradiation. The deuterium leak rates are within the background levels, and the tested tubes still have gas tightness. Finite element analysis [16] indicated that the residual tensile axial and hoop stresses at the inner surface of CVD SiC tube following irradiation under high heat flux are $\sim 200 \mathrm{MPa}$, resulting from the differential swelling rates stemming from the $64^{\circ} \mathrm{C}$ temperature difference across the tube thickness. It also indicates a large probability of cracking in the areas close to the inner surface. On the other hand, the cracking near the outer surface of the cladding is less likely because of the compression stress state along both the axial and hoop directions. In order to confirm the presence of cracking, Singh et al. [17] examined two CVD SiC tubes following the same neutron irradiation conditions and found that the change in the elastic modulus (determined by using Resonant Ultrasound Spectroscopy) as a function of swelling was inconstant with the literature data obtained from neutron irradiated CVD SiC tubes without a high heat flux (the low heat flux case). The difference was attributed to the existence of micro-cracking in the studied samples. The cross sectional optical microscopy images of one irradiated $\mathrm{SiC}$ tube clearly showed the presence of cracks with some cracks originating from the inner surface and terminating halfway through the thickness. However, the hermetic performance of the two CVD SiC tubes tested in the current study implied that no penetrating cracking across the tube thickness was developed or there is no cracking. 

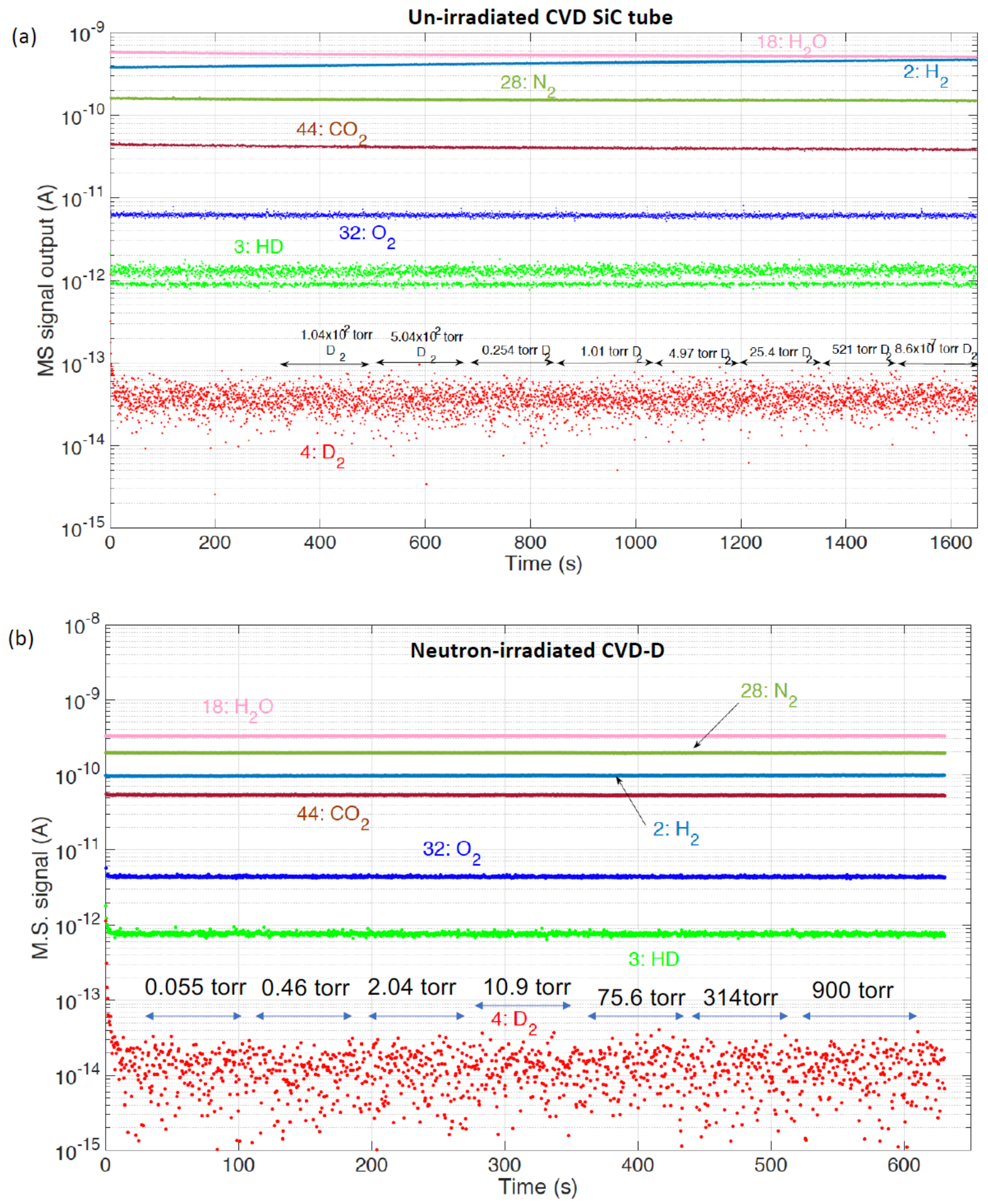


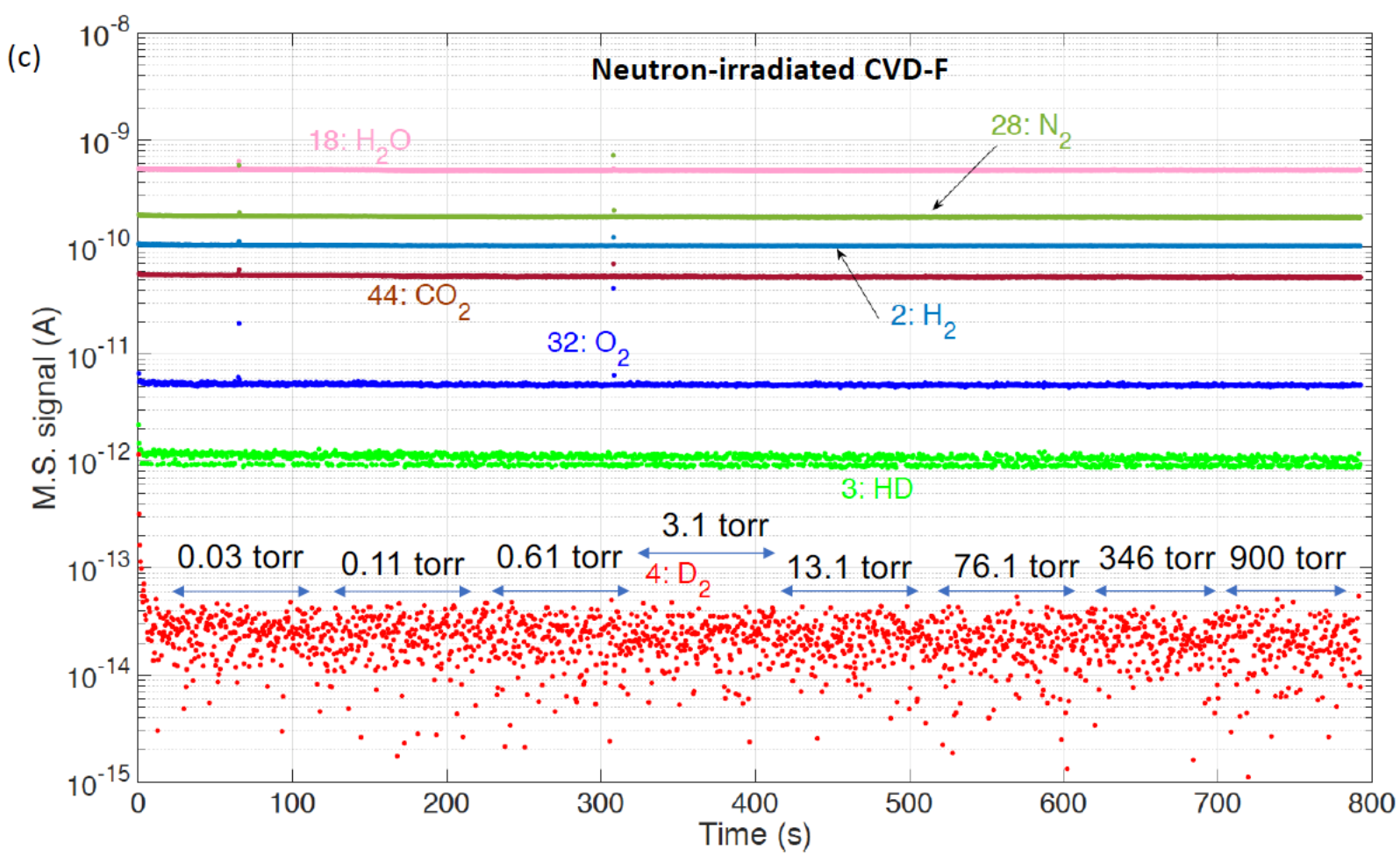

Figure 1. Deuterium permeation testing of (a) unirradiated CVD SiC tube, (b) CVD SiC-D following high heat flux neutron irradiation, and (c) CVD SiC-F following high heat flux neutron irradiation. Important gases in the background are also shown.

\subsection{Deuterium permeation of neutron-irradiated SiC/SiC composite tubes}

The measured deuterium leak rates of neutron irradiated $\mathrm{SiC} / \mathrm{SiC}$ tubes under high and low heat flux as a function of deuterium pressure are shown in Figure 2. All tested tubes following neutron irradiation under high and low heat flux lost the gas tightness except the GA-TGI-C2 tube. Deuterium leak rate increases with increasing pressure and starts to level off when pressure is greater than 50 torr. For example, SA3-4 lost gas tightness with a relatively smaller deuterium leak rate $\left(1.31 \times 10^{-9} \mathrm{~atm}-\mathrm{cc} / \mathrm{sec}\right)$ when tested at a deuterium pressure of $1.27 \times 10^{-2}$ torr. When subject to higher deuterium pressure, the measured deuterium leak first increased and started to reach saturation with an ultimate leak rate of $8.72 \times 10^{-7} \mathrm{~atm}$ $\mathrm{cc} / \mathrm{sec}$. The deuterium leak rate of GA-TGI-C1 is much larger than those of other tubes and the measurement of the deuterium permeation under high pressure ( $>5$ torr) was not attempted due to the significantly large permeation flux potentially impacting the mass spectrometer. It is noted that high heat flux neutron irradiation leads to higher deuterium leak rate of the studied samples in comparison with those following low heat flux irradiation, e.g., SA3-1 (LHF) and SA3-4 (HHF), GA-TGI-C2 (LHF) and GA-TGI-C1 (HHF). Loss of hermeticity of the studied samples indicates the presence of penetrating cracks. 


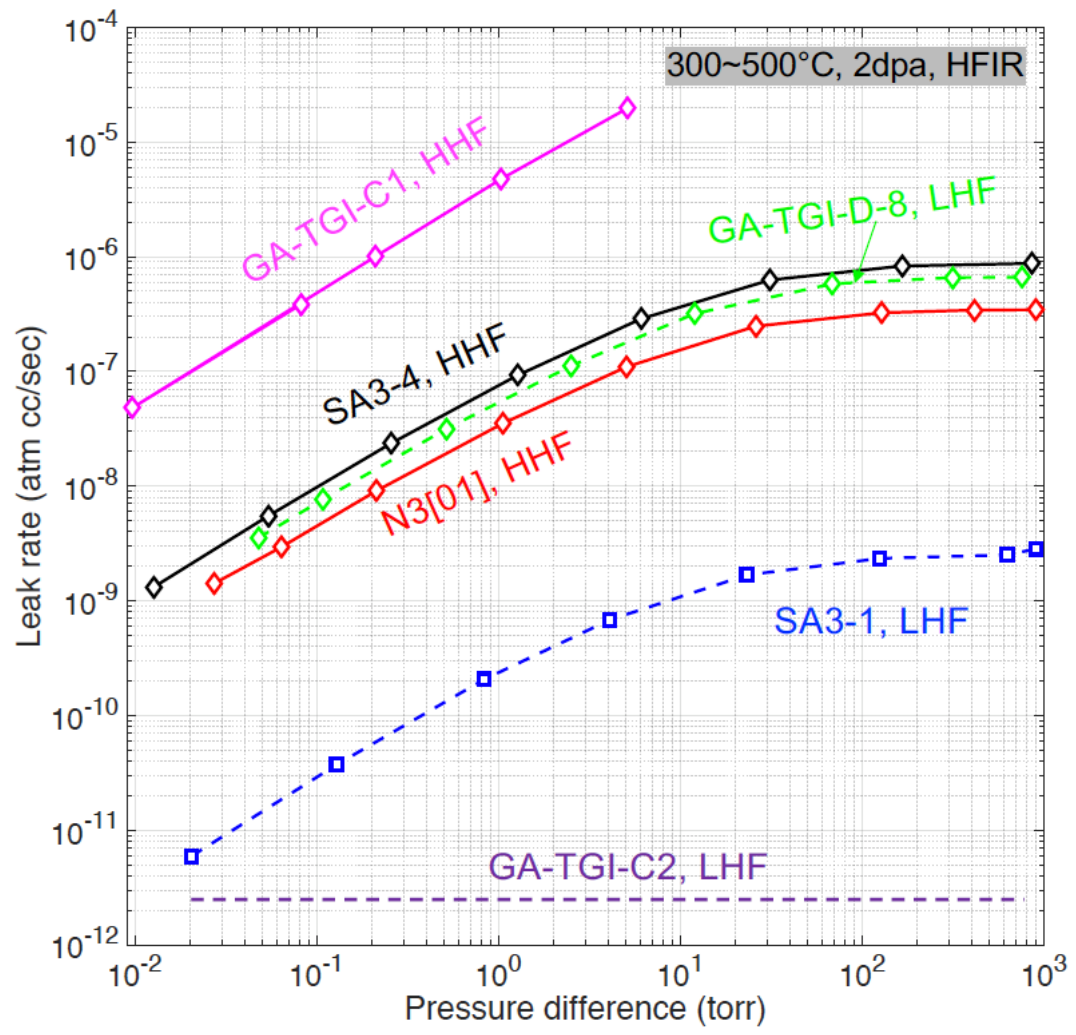

Figure 2. Deuterium leak rate of $\mathrm{SiC} / \mathrm{SiC}$ composite tubes following neutron irradiation $\left(300 \sim 500^{\circ} \mathrm{C}\right.$, $2 \mathrm{dpa}, \mathrm{HFIR}$ ) under high (HHF) and low (LHF) heat flux as a function of deuterium pressure within the tubes.

Finite element analysis [16] showed that a large temperature difference of $150^{\circ} \mathrm{C}$ was present across the thickness of the $\mathrm{SiC} / \mathrm{SiC}$ composite tubes following neutron irradiation under high heat flux, which is larger than that of CVD SiC tube under the same irradiation condition due to the lower thermal conductivity of $\mathrm{SiC} / \mathrm{SiC}$ composite tubes. Larger temperature difference gave rise to larger differential swelling rates. However, simulation showed that the tensile axial and hoop stresses are $\sim 170 \mathrm{MPa}$, smaller than that of CVD $\mathrm{SiC}$ tubes rationalized by the smaller elastic modulus of $\mathrm{SiC} / \mathrm{SiC}$ composite tubes. The microcracking in the matrix of $\mathrm{SiC} / \mathrm{SiC}$ composites develops when the proportional limit strength (PLS, which is $\sim 65 \mathrm{MPa}$ [18]) is reached, or even under the condition of less than PLS[19]. The expected stress level in the samples following high heat flux neutron irradiation is large enough to induce the cracking. Resonant Ultrasound Spectroscopy (RUS) was used to determine the elastic modulus of irradiated $\mathrm{SiC} / \mathrm{SiC}$ samples. Significant bulk elastic moduli reduction $(>13 \%)$ was observed, attributed to the presence of microcracking[20]. More post irradiation examinations are being performed to characterize the pathways of helium leaking and will be published elsewhere.

\subsection{Deuterium permeation of neutron-irradiated coated SiC/SiC composite tubes}

External coating has been perceived as an effective way to improve hermeticity of $\mathrm{SiC} / \mathrm{SiC}$ composite fuel cladding as well as the hydrothermal corrosion resistance. $\mathrm{SiC} / \mathrm{SiC}$ composite tubes coated with $\mathrm{TiN}$, $\mathrm{CrN}$, and $\mathrm{Cr}$ showed hermetic performance under unirradiated conditions [14]. The results of hermeticity 
testing of coated GA samples, shown in Figure 3, indicated that $\mathrm{Cr}$ - and $\mathrm{CrN}$-coated GA tubes survived the low heat flux neutron irradiation and retained gas tightness. Note that the same type of $\mathrm{SiC} / \mathrm{SiC}$ tube (GA-TGI-D8) without coating completely lost its hermeticity following the 2 dpa irradiation in HFIR under low heat flux. In contrast, gas tightness of TiN-coated GA-TGI-D3 was not maintained following the high radial heat flux neutron irradiation. However, the deuterium leak rate of this coated sample is estimated to be much lower than that of the uncoated one (GA-TGI-D4) following same irradiation condition. Significant leaking was observed when GA-TGI-D4 was exposed to atmosphere. High pressure testing was not attempted considering the safety of the mass spectrometer. Although the data is limited, the coating does play a role to reduce the deuterium leak rate in the case of the high heat flux radiation and to maintain the hermeticity of low heat flux samples.

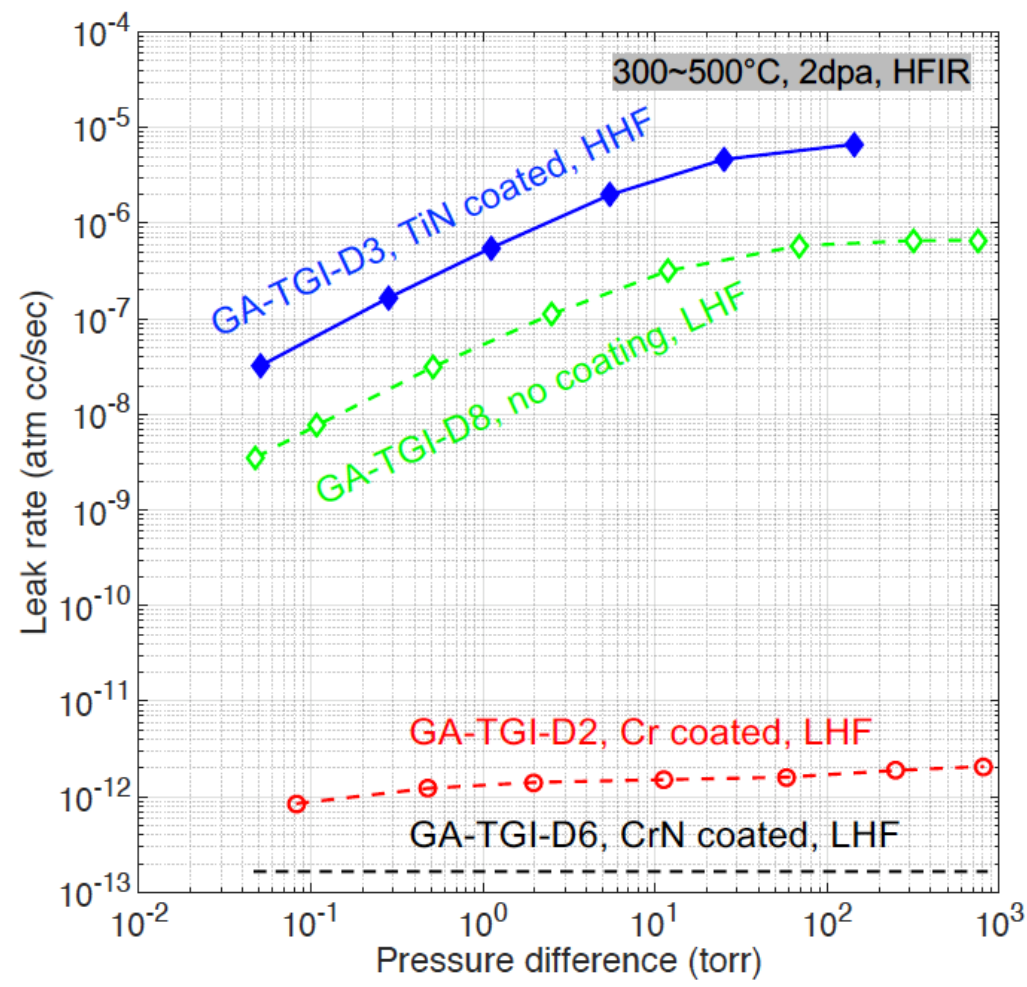

Figure 3. Deuterium leak rate of coated $\mathrm{SiC} / \mathrm{SiC}$ composite tubes following neutron irradiation $\left(300 \sim 500^{\circ} \mathrm{C}, 2 \mathrm{dpa}, \mathrm{HFIR}\right)$ under high and low heat flux as a function of helium pressure within the tubes.

It is noted that the coatings tested in the current report are the first-generation ones. ORNL has developed the $2^{\text {nd }}$ generation coating which is expected to have better performance with respect to hermeticity. Hermeticity of $\mathrm{SiC} / \mathrm{SiC}$ composite cladding can be achieved by improved architectures, improved tube fabrication quality, and improved coating.

\section{DISCUSSION}

It has been hypothesized that the gas leak rate through a tubular SiC-based sample is proportional to the gas pressure and sample surface area [21]. This assumption is based on the well-known Hagen-Poiseuille model. If assuming a long straight cylindrical pipe with constant cross section is the helium pass, the leak rate is 


$$
Q=\frac{\pi R^{4}}{8 \mu L} \Delta P
$$

where $\Delta P$ is the pressure difference, $\mathrm{Q}$ is the gas leak rate, $\mathrm{L}$ is the length of pipe, $\mathrm{R}$ is the radius, $\mu$ is the dynamic viscosity of the fluid. However, the potential path for gas leaking through the $\mathrm{SiC} / \mathrm{SiC}$ composite tube is the much more complicated interlinked microcracking. It is apparent that the Hagen-Poiseuille model is not applicable in the current case, as shown in Figure 4. However, a well-established model accurately describing the underlying mechanism controlling the gas flow in $\mathrm{SiC} / \mathrm{SiC}$ tubes is unavailable up to now.

A comparison of helium and deuterium permeation flux through SA3-4 shown in Figure 4 indicates that deuterium permeation flux is higher than that of helium under the same applied pressure, given the lower dynamic viscosity of deuterium. In Ref. [14], the preliminary results showed opposite correlation due to the inaccurate conversion coefficient used to convert the electrical current to atom flux based on the standard deuterium leak. Our results also showed that deuterium and helium permeation flux reach saturation when applied pressure is greater than 50 torr within the studied pressure regime. It is still unknown whether this trend will be changed when pressure is continuously increasing. High pressure gas permeation testing is needed.

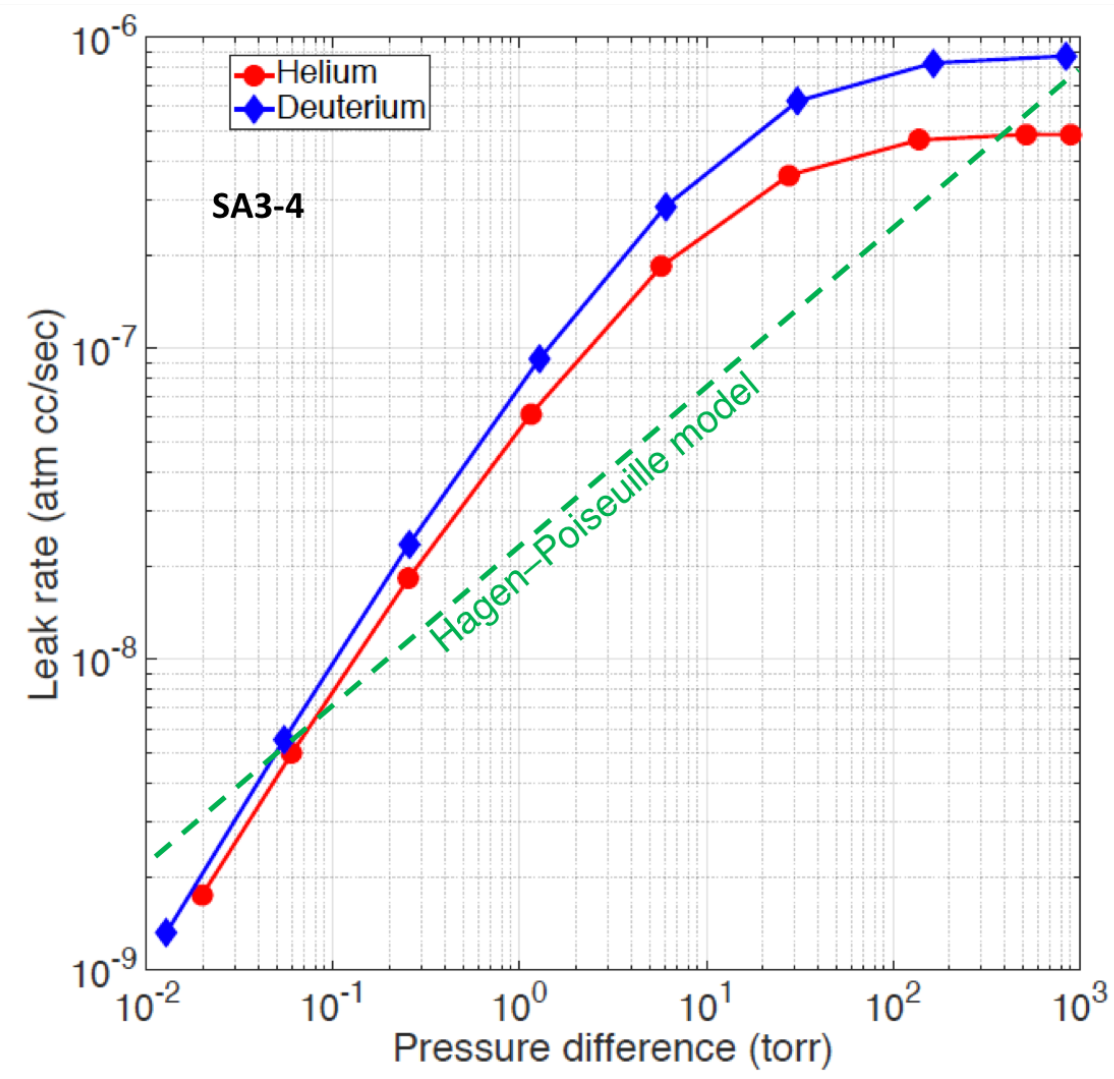

Figure 4. Helium and deuterium permeation flux of SA3-4 following high heat flux neutron irradiation as a function of feeding gas pressure. Dashed line is the prediction using Hagen-Poiseuille model.

\section{SUMMARY AND FUTURE WORK}


This report summarizes our recent efforts to measure deuterium permeation through $\mathrm{SiC} / \mathrm{SiC}$ composite tubes following neutron irradiation under representative LWR application environment. The deuterium permeation flux was measured using the ORNL comprehensive permeation testing station. The results indicate that CVD SiC tubes survived both the high and low heat flux neutron irradiations. SiC/SiC composite tubes with and without coating following high heat flux neutron irradiation lost the gas tightness. Coating on $\mathrm{SiC} / \mathrm{SiC}$ composite tubes helped to reduce the deuterium permeation flux compared to the uncoated samples. Better coating is needed to ensure the hermeticity of $\mathrm{SiC} / \mathrm{SiC}$ composite tubes. A more robust understanding of the correlation between applied gas pressure and measured leak rate is needed.

More work will be performed to characterize the neutron-irradiated SiC/SiC tubes to identify the pathway of gas leaking, enabling the mechanistic understanding of driving forces of the gas leaking. In addition, better processing and coating are needed to ensure the hermeticity of the $\mathrm{SiC} / \mathrm{SiC}$ composite tubes following neutron irradiation.

\section{REFERENCES}

1. Zinkle, S.J., et al., Accident tolerant fuels for LWRs: A perspective. Journal of Nuclear Materials, 2014. 448(1-3): p. 374-379.

2. Zinkle, S.J., K.A. Terrani, and L.L. Snead, Motivation for utilizing new high-performance advanced materials in nuclear energy systems. Current Opinion in Solid State and Materials Science, 2016. 20(6): p. 401-410.

3. Terrani, K.A., S.J. Zinkle, and L.L. Snead, Advanced oxidation-resistant iron-based alloys for LWR fuel cladding. Journal of Nuclear Materials, 2014. 448(1-3): p. 420-435.

4. $\quad$ Pint, B.A., et al., High temperature oxidation of fuel cladding candidate materials in steamhydrogen environments. Journal of Nuclear Materials, 2013. 440(1-3): p. 420-427.

5. Rosa, C.J., Oxidation of zirconium-A critical review of literature. Journal of the Less Common Metals, 1968. 16(3): p. 173-201.

6. Katoh, Y. and K.A. Terrani, Systematic Technology Evaluation Program for SiC/SiC Compositebased Accident-Tolerant LWR Fuel Cladding and Core Structures. ORNL/TM-2015/454, 2015.

7. Causey, R.A., et al., Tritium migration in vapor-deposited beta-silicon carbide. Journal of Nuclear Materials, 1993. 203: p. 196-205.

8. Causey, R.A., et al., Hydrogen diffusion and solubility in silicon carbide. Journal of The American Ceramic Society, 1978. 61: p. 221-225.

9. Hino, T., et al., Helium gas permeability of SiC/SiC composite used for in-vessel components of nuclear fusion reactor. Fusion Engineering and Design, 2005. 73(1): p. 51-56.

10. Hino, T., et al., Helium gas permeability of SiC/SiC composite after heat cycles. Journal of Nuclear Materials, 2007. 367-370: p. 736-741.

11. Deck, C.P., et al., Characterization of SiC-SiC composites for accident tolerant fuel cladding. Journal of Nuclear Materials, 2015. 466: p. 667-681.

12. Khalifa, H.E., et al., Fabrication and characterization of joined silicon carbide cylindrical components for nuclear applications. Journal of Nuclear Materials, 2015. 457: p. 227-240.

13. $\mathrm{Hu}, \mathrm{X}$., et al., Hydrogen permeation in FeCrAl alloys for LWR cladding application. Journal of Nuclear Materials, 2015. 461: p. 282-291.

14. $\mathrm{Hu}, \mathrm{X}$., et al., Determination of He and D permeability of neutron-irradiated SiC tubes to examine the potential for release due to micro-cracking. ORNL/TM-2017/362, 2017.

15. Petrie, C.M., et al., Experimental design and analysis for irradiation of SiC/SiC composite tubes under a prototypic high heat flux. Journal of Nuclear Materials, 2017. 491: p. 94-104. 
16. Singh, G., K. Terrani, and Y. Katoh, Thermo-mechanical assessment of full SiC/SiC composite cladding for LWR applications with sensitivity analysis. Journal of Nuclear Materials, 2018. 499: p. 126-143.

17. Singh, G., et al., Evaluating the irradiation effects on the elastic properties of miniature monolithic SiC tubular specimens. Journal of Nuclear Materials, 2018. 499: p. 107-110.

18. Singh, G., et al., Interlaboratory round robin study on axial tensile properties of SiC-SiC CMC tubular test specimens. International Journal of Applied Ceramic Technology, 2018.

19. Nozawa, T., K. Ozawa, and H. Tanigawa, Re-defining failure envelopes for silicon carbide composites based on damage process analysis by acoustic emission. Fusion Engineering and Design, 2013. 88(9-10): p. 2543-2546.

20. Singh, G., et al., Elastic Moduli Reduction in SiC-SiC Tubular Specimen after High Heat Flux Neutron Irradiation Measured by Resonant Ultrasound Spectroscopy. To be published, 2019.

21. Gutierrez, O., et al., Permeability measurements for SiC ceramic matrix composites relevant to LWR. Transactions of the American Nuclear Society, 2014. 110: p. 803-806. 